\title{
IMPLEMENTASI METODE HOLT WINTER ADDITIVE UNTUK PREDIKSI KUNJUNGAN WISATAWAN NUSANTARA KABUPATEN SUMENEP
}

\author{
Ainun Nawawi ${ }^{1)}$, Sri Herawati ${ }^{2)}$, Novi Prastiti ${ }^{3)}$ \\ ${ }^{1,2,3}$ Prodi Sistem Informasi, Fakultas Teknik, Universitas Trunojoyo Madura \\ Jl. Raya Telang, PO BOX 2 Kamal, Bangkalan \\ E-mail : ${ }^{1} 170441100110 @$ student.trunojoyo.ac.id, ${ }^{2}$ sriherawati@trunojoyo.ac.id, \\ ${ }^{3}$ prastitinovi@ trunojoyo.ac.id
}

\begin{abstract}
ABSTRAK
Adanya peningkatan kunjungan wisatawan di Kabupaten Sumenep yang tidak dapat diduga, sehingga perlu dilakukan peramalan untuk memprediksi jumlah kunjungan wisatawan di Kabupaten Sumenep pada periode yang akan datang. Dalam kesempatan penelitian kali ini dilakukan peramalan kunjungan wisatawan di Kabupaten Sumenep menggunakan metode hold-winters exponential smoothing additive, metode hold-winters exponential smoothing additive merupakan metode yang didasarkan pada tiga persamaan smoothing yaitu smoothing level, smoothing trend, serta smoothing musim. Data yang digunakan dalam penelitian ini berupa data time series kunjungan wisatawan Kabupaten Sumenep dari bulan Januari 2015 - Februari 2020. Hasil dari penelitian yang telah dilakukan diperoleh nilai akurasi peramalan SMAPE terbaik sebesar 13,65\%, dengan nilai $\alpha=$ 0,$01 ; \beta=0,01 ; \gamma=0,37$. Berdasarkan hasil nilai akurasi peramalan SMAPE yang telah didapat, metode peramalan hold-winters exponential smoothing additive dapat menjadi rujukan untuk penyusunan strategi pembangunan dan pemasaran wisata di Kabupaten Sumenep. Sehingga dapat meningkatkan efektivitas dalam pengambilan keputusan dan meningkatkan perekonomian di Kabupaten Sumenep.
\end{abstract}

Kata kunci : Peramalan, Kunjungan Wisatawan, Holt Winter Eksponensial Smoothing Additive.

\begin{abstract}
There is an enhancement of unexpected tourists visitation in Sumenep district; therefore, it should be conducted forecasting to predict the number of tourists visitation in Sumenep district in future period. In this chance of study, researcher conducted forecasting of tourists visitation in Sumenep district using Hold-Winters exponential smoothing additive method. Hold-Winters exponential smoothing additive method is a method based on 3 similarities of smoothing which are smoothing of level, smoothing of trend, and smoothing of season. Used data in this study was in form of time series data dealing with tourists visitation in Sumenep district from January 2015 until February 2020. Result of this conducted study was gained value of best forecasting accuracy of SMAPE by $13,65 \%$, with the value $\alpha=0,01 ; \beta=0,01 ; \gamma=0,37$. Based on the obtained result of the value of forecasting accuracy of SMAPE, Hold-Winters exponential smoothing additive can be as a reference for building structuring and travel marketing in Sumenep district. Thus, it can increase effectiveness of decision-making and enhance economy in Sumenep district.
\end{abstract}

Keywords: Forecasting, Tourist Visit, Holt Winter Exponential Smoothing Additive. 


\section{PENDAHULUAN}

Pariwisata merupakan kegiatan yang sering dilakukan oleh setiap orang, terutama pada saat hari libur atau hari-hari tertentu. Dalam pariwisata biasanya orang-orang akan mengunjungi tempat wisata yang ada di daerah tertentu. Di kabupaten Sumenep Madura banyak tempat wisata yang dapat wisatawan kunjungi seperti halnya pantai, museum, keraton, makam tokoh publik dan lain sebagainya. Data statistik pada tahun 2015-2019 jumlah kunjungan wisatawan di kabupaten Sumenep Madura mengalami peningkatan [1], hal ini dapat dilihat pada Gambar 1.

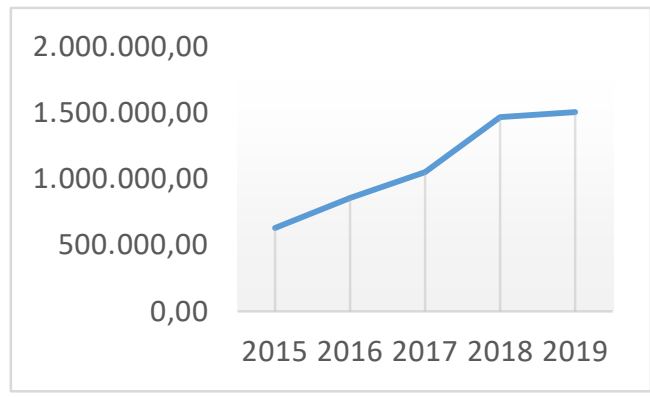

Gambar 1. Jumlah pengunjung dari tahun 2015-2019

Berdasarkan data statistik di Gambar 1, dapat disimpulkan bahwa wisata di kabupaten Sumenep mulai diminati oleh para wisatawan. Sehingga perlu dilakukan sebuah peramalan jumlah kunjungan wisatawan di Kabupaten Sumenep Madura pada masa yang akan datang, guna untuk meningkatkan strategi pengelolaan wisata serta efektivitas pengambilan keputusan dalam mempertahankan atau meningkatkan penghasilan ekonomi dari sektor pariwisata.

Peramalan merupakan proses analisis yang dilakukan untuk mengetahui apa yang akan terjadi pada masa yang akan datang berdasarkan faktor-faktor variabel yang berkaitan atau pola data historis yang ada [2][3][4]. Banyak metode peramalan yang dapat diterapkan untuk melakukan peramalan kunjungan wisatawan, salah satunya merupakan metode holt-winter exponential smoothing additive yang telah diterapkan pada sebuah penelitian berjudul "Metode Pemulusan Eksponensial Holt-Winters untuk Peramalan Data Deret Waktu Musiman" Studi Kasus Data Jumlah kedatangan Wisatawan Mancanegara Melalui Bandara Ngurah Rai Tahun 2008-2016, dalam penelitian tersebut dilakukan peramalan menggunakan metode holtwinter exponential smoothing additive dan multiplicative, hasil dari penelitian tersebut didapat nilai Mean Absolute Precentage Error (MAPE) terkecil sebesar $5,43 \%$ dengan keunggulan metode holtwinter exponential smoothing additive [5]. Sehingga metode tersebut dapat diterapkan untuk melakukan peramalan jumlah kunjungan wisatawan pada beberapa periode yang akan datang.

\section{METODE}

\section{a. Exponential smoothing}

Exponential smoothing merupakan salah satu metode peramalan yang telah banyak diterapkan dan dikembangkan. Metode ini memberikan bobot exponential moving average untuk semua data historis, tujuannya adalah untuk mengestimasi nilai level terkini dan menggunakannya untuk mencari hasil peramalan beberapa periode ke depan. Persamaan simple exponential smoothing didefinisikan sebagai berikut [2][6].

1. Inisialisasi peramalan:

$$
F_{1}=y_{1}
$$

2. Peramalan untuk 1 periode ke depan:

$$
F_{t+1}=\alpha y_{t}+(1-\alpha) F_{t}
$$

\section{b. Holt's exponential smoothing}

Metode exponential smoothing telah banyak dikembangkan salah satunya metode Holt's exponential smoothing. Metode holt's exponential smoothing adalah perluasan dari simple exponential smoothing dengan dua parameter ( $\alpha$ dan $\beta$ ). Metode ini menambahkan faktor trend (faktor pertumbuhan) dalam persamaan smoothing, untuk menyesuaikan dengan pola data yang mengandung trend. Persamaan metode holt's exponential 
smoothing didefinisikan sebagai berikut [2][6].

1. Inisialisasi exponential estimasi level, persamaan ini sama dengan persamaan (1) pada simple exponential smoothing.

2. Inisialisasi exponential estimasi trend:

$$
\begin{gathered}
b_{1}=y_{2}-y_{1} \\
\text { atau } \\
b_{1}=\frac{\sum_{t=1}^{3}\left(y_{t+1}-y_{t}\right)}{3} \\
b_{1}=\frac{y_{n}-y_{1}}{n-1}
\end{gathered}
$$

3. Exponential smoothing estimasi level:

$L_{t}=\alpha y_{t}+(1-\alpha)\left(L_{t-1}+b_{t-1}\right)$

4. Exponential smoothing estimasi trend:

$b_{t}=\beta\left(L_{t}-L_{t-1}\right)+(1-\beta) b_{t-1}$

5. Peramalan untuk periode $t$ :

$$
F_{t}=L_{t}+b_{t}
$$

6. Peramalan untuk periode $t+m$ :

$$
F_{t+m}=L_{t}+m b_{t}
$$

\section{c. Holt-Winter \\ Smoothing}

Exponential

Perluasan berikutnya dari exponential smoothing model adalah metode winter's exponential smoothing atau disebut juga holt-winter exponential smoothing. Metode ini menggunakan tiga parameter $(\alpha, \beta$, dan $\gamma)$. Metode ini digunakan pada data yang memiliki pola trend dan musiman, terdapat tambahan satu persamaan yang digunakan untuk menyesuaikan komponen musimannya. Pada dasarnya terdapat dua tipe metode holt-winter exponential smoothing, yaitu holt-winter exponential smoothing additive dan multiplicative.

Metode holt-winter exponential smoothing additive cocok digunakan untuk meramalkan data yang mengandung pola data trend dan musiman dengan fluktuasi data yang tidak begitu signifikan. Adapun persamaan metode holt-winter exponential smoothing didefinisikan sebagai berikut [2]:

1. Inisialisasi exponential estimasi level:

$$
L_{s}=\frac{\sum_{n=1}^{s} y_{n}}{s}
$$

2. Inisialisasi exponential estimasi trend:

$$
b_{s}=\frac{\sum_{n=1}^{s} y_{s+n}-y_{n}}{s^{2}}
$$

3. Inisialisasi exponential estimasi musim:

$S_{1}=y_{1}-L_{s} ; \ldots ; S_{s}=y_{s}-L_{s}$

4. Exponential smoothing estimasi level:

$L_{t}=\alpha\left(y_{t}-S_{t-s}\right)+(1-\alpha)\left(L_{t-1}+b_{t-1}\right)$

5. Exponential smoothing estimasi trend:

$b_{t}=\beta\left(L_{t}-L_{t-1}\right)+(1-\beta) b_{t-1}$

6. Exponential smoothing estimasi musim:

$S_{t}=\gamma\left(y_{t}-L_{t}\right)+(1-\gamma) S_{t-s}$

7. Peramalan untuk periode $t$ :

$$
F_{t}=L_{t-1}+b_{t-1}+S_{t-s}
$$

8. Peramalan untuk periode $t+m$ :

$$
F_{t+m}=L_{t}+m b_{t}+S_{t+m-s}
$$

\section{d. Symmetric Mean Absolute} Percentage Error (SMAPE)

Akurasi peramalan merupakan proses pengukuran seberapa akurat metode yang digunakan dapat meramalkan data. Pada penelitian ini akurasi peramalan diukur menggunakan persamaan SMAPE, SMAPE merupakan pengukuran nilai akurasi berdasarkan persentase kesalahan (error) [7]. Adapun persamaan SMAPE dideskripsikan sebagai berikut [8]:

$$
S M A P E=\frac{100 \%}{n} \sum_{t=s+1}^{n} \frac{\left|F_{t}-y_{t}\right|}{\left|y_{t}\right|+\left|F_{t}\right|}
$$

\section{e. Desain Peramalan}

Berdasarkan persamaan holt-winter exponential smoothing additive terbentuklah desan model peramalan sebagaimana terdapat pada Gambar 2 pada penelitian ini. Gamabar 2 menjelaskan alur metode peramalan dimulai dari data yang input-kan, kemudian dilakukan inisialisasi exponential estimasi (level, trend, musim) serta exponential smoothing estimasi (level, trend, musim) hingga mendapatkan hasil peramalan. 


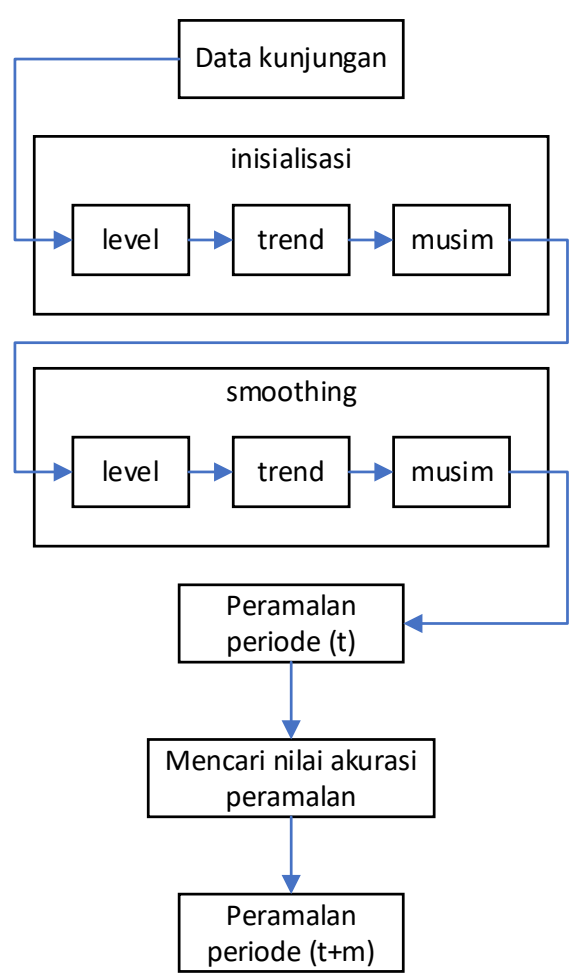

Gambar 2. Desain model peramalan

Berikut merupakan penjelasan mendetail dari masing-masing proses yang di terapkan pada Gambar 2:

1. Input data pengunjung.

2. Data yang di-input-kan akan dilakukan proses inisialisasi exponential estimasi level menggunakan persamaan (10), inisialisasi exponential estimasi trend menggunakan persamaan (11), dan inisialisasi exponential estimasi musim menggunakan persamaan (12).

3. Setelah inisialisasi exponential dilakukan, proses selanjutnya adalah exponential smoothing estimasi level menggunakan persamaan (13), exponential smoothing estimasi trend menggunakan persamaan (14), dan exponential smoothing estimasi musim menggunakan persamaan (15).

4. Setelah proses exponential smoothing dilakukan proses peramalan periode $t$ menggunakan persamaan (16) untuk memperoleh hasil peramalan pada periode $t$.
5. Setelah melakukan peramalan pada periode $t$, proses selanjutnya mencari nilai akurasi peramalan.

6. Setelah mendapatkan nilai akurasi peramalan terkecil, proses selanjutnya melakukan peramalan pada periode $t+m$.

\section{HASIL DAN PEMBAHASAN}

Dalam penelitian ini data yang digunakan merupakan data time series kunjungan wisatawan nusantara di Kabupaten Sumenep dalam kurun waktu bulan dari Januari 2015 - Februari 2020.

1. Input data

Sebagaimana langkah pertama pada Gambar 2 dilakukan persiapan data kunjungan Kabupaten Sumenep untuk diinput-kan ke dalam sistem Adapun data kunjungan bisa dilihat pada Tabel 1.

Tabel 1. Data kunjungan wisata Januari 2015 - Februari 2020

\begin{tabular}{ccc}
\hline $\begin{array}{c}\text { Periode } \\
(\boldsymbol{t})\end{array}$ & Tanggal & Kunjungan \\
\hline 1 & Jan-15 & $60.819,00$ \\
2 & Feb-15 & $31.657,00$ \\
3 & Mar-15 & $32.893,00$ \\
$\ldots$ & $\ldots$ &.. \\
62 & Feb-20 & $90.948,00$ \\
\hline
\end{tabular}

2. Inisialisasi Exponential

Langkah selanjutnya melakukan inisialisasi exponential estimasi level, trend, dan musim dengan persamaan yang telah didefinisikan (10)(11)(12), dengan panjang musim yang digunakan 12 bulan $(s=12)$ sehingga hasil inisialisasi exponential yang diperoleh sebagaimana pada Tabel 2.

Tabel 2. Hasil inisialisasi exponential data

\begin{tabular}{|c|r|r|r|}
\multicolumn{5}{|c|}{ kunjungan } \\
\hline $\boldsymbol{t}$ & $\boldsymbol{L}_{\boldsymbol{t}}$ & \multicolumn{1}{|c|}{$\boldsymbol{b}_{\boldsymbol{t}}$} & \multicolumn{1}{c|}{$\boldsymbol{S}_{\boldsymbol{t}}$} \\
\hline 1 & - & - & $8.575,17$ \\
\hline 2 & - & - & $-20.586,83$ \\
\hline 3 & - & - & $-19.350,83$ \\
\hline$\ldots$ & $\ldots$ & $\ldots$ & $\ldots$ \\
\hline 12 & $52.243,83$ & $1.581,17$ & $30.137,17$ \\
\hline
\end{tabular}

3. Exponential Smoothing

Setelah melakukan proses inisialisasi exponential langkah selanjutnya melakukan proses exponential smoothing estimasi level, trend, dan musim dengan persamaan yang telah 
didefinisikan (13)(14)(15), dengan nilai $\alpha=0,01 ; \beta=0,01 ; \gamma=0,37$

Sehingga hasil exponential smoothing dapat dilihat pada Tabel 3.

Tabel 3. Hasil exponential smoothing data kunjungan

\begin{tabular}{cccr}
\hline $\boldsymbol{t}$ & $\boldsymbol{L}_{\boldsymbol{t}}$ & $\boldsymbol{b}_{\boldsymbol{t}}$ & \multicolumn{1}{c}{$\boldsymbol{S}_{\boldsymbol{t}}$} \\
\hline 13 & $53.791,14$ & $1.580,83$ & $7.368,34$ \\
14 & $55.505,04$ & $1.582,16$ & - \\
& & & $15.844,27$ \\
15 & $57.249,89$ & $1.583,79$ & - \\
$\ldots$ & $\ldots$ & $\ldots$ & $\ldots$ \\
62 & $134.004,09$ & $1.600,99$ & - \\
& & & $31.801,68$ \\
\hline
\end{tabular}

4. Peramalan Periode ( $\mathrm{t}$ )

Setelah proses exponential smoothing dilakukan, langkah selanjutnya melakukan proses peramalan pada periode $t$ Dengan persamaan yang telah didefinisikan (16), sehingga hasil peramalan pada periode $t$ yang diperoleh dapat dilihat pada Tabel 4.

Tabel 4. Hasil peramalan Periode $(\boldsymbol{t})$

\begin{tabular}{ccc}
\hline $\boldsymbol{t}$ & Tanggal & $\boldsymbol{F}_{\boldsymbol{t}}$ \\
\hline 13 & Jan-16 & $62.400,00$ \\
14 & Feb-16 & $34.785,00$ \\
15 & Mar-16 & $37.736,00$ \\
$\ldots$ & $\ldots$ & $\ldots$ \\
62 & Feb-20 & $108.710,00$ \\
\hline
\end{tabular}

Pola data grafik hasil peramalan yang dilakukan pada periode $t$ dapat dilihat pada Gambar 3.

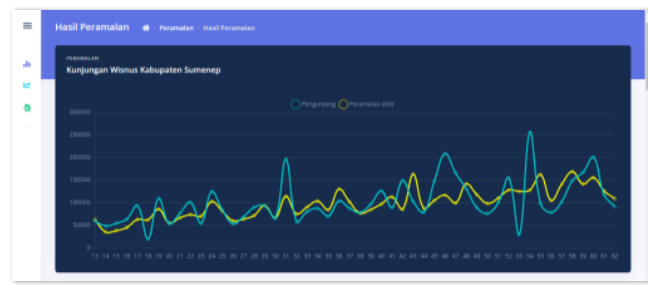

Gambar 3. Hasil peramalan Periode $(\boldsymbol{t})$

5. Menghitung Akurasi Peramalan

Setelah proses peramalan pada periode $t$ dilakukan, langkah selanjutnya menghitung nilai akurasi peramalan yang diperoleh, dengan menggunakan persamaan SMAPE (18). Sehingga nilai yang diperoleh sebesar:

$$
\begin{gathered}
\text { SMAPE }=\frac{100 \%}{50} \times 6,83 \\
\text { SMAPE }=13,66 \%
\end{gathered}
$$

Dalam penelitian ini, langkah 3-5 terus diulang, dengan perubahan nilai $\alpha$, $\beta$, dan $\gamma$ hingga mendapatkan nilai SMAPE terkecil, yaitu sebesar $13,65 \%$ dengan nilai $\alpha=0,01 ; \beta=0,01 ; \gamma=$ 0,36 .

6. Hasil Peramalan Periode $(t+m)$

Langkah akhir dari penelitian peramalan ini setelah mendapatkan nilai SMAPE dan nilai $\alpha, \beta, \gamma$ terbaik, langkah selanjutnya melakukan peramalan beberapa periode ke depan dengan menggunakan persamaan (17). Hasil dari peramalan beberapa periode ke depan dapat dilihat pada Tabel 5 .

Tabel 5.Hasil peramalan Periode $(\boldsymbol{t}+\boldsymbol{m})$

\begin{tabular}{ccc}
\hline $\boldsymbol{t}+\boldsymbol{m}$ & Tanggal & $\boldsymbol{F}_{\boldsymbol{t}}$ \\
\hline 63 & Mar-20 & $124.462,00$ \\
64 & Apr-20 & $156.055,00$ \\
65 & Mei-20 & $109.117,00$ \\
$\ldots$ & $\ldots$ & $\ldots$ \\
74 & Feb-21 & $121.414,00$ \\
\hline
\end{tabular}

Pola data grafik hasil peramalan yang dilakukan pada periode $t+m$ dapat dilihat pada Gambar 4.

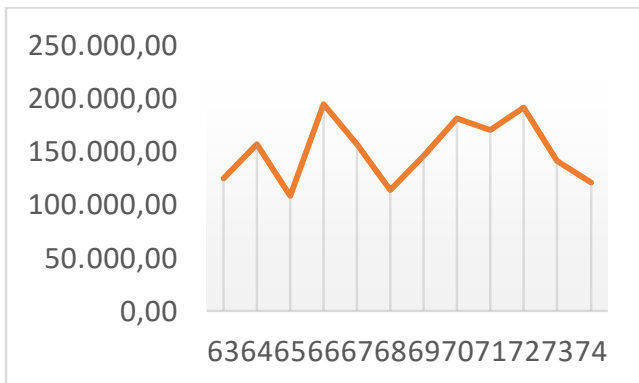

Gambar 4. Hasil peramalan Periode $(\boldsymbol{t}+\boldsymbol{m})$

\section{SIMPULAN}

Dalam penelitian ini dapat disimpulkan bahwa metode holt-winter exponential smoothing additive dapat diterapkan sebagai acuan kajian perancangan strategi pembangunan dan pemasaran wisata di Kabupaten Sumenep. Hal ini dapat kita lihat dari hasil nilai akurasi peramalan SMAPE yang diperolah sebesar $13,65 \%$, dengan nilai 
$\alpha=0,01 ; \beta=0,01 ; \gamma=0,37$. Nilai SMAPE tersebut sudah termasuk dalam kategori akurat dalam meramalkan data kunjungan wisata di Kabupaten Sumenep.

\section{SARAN}

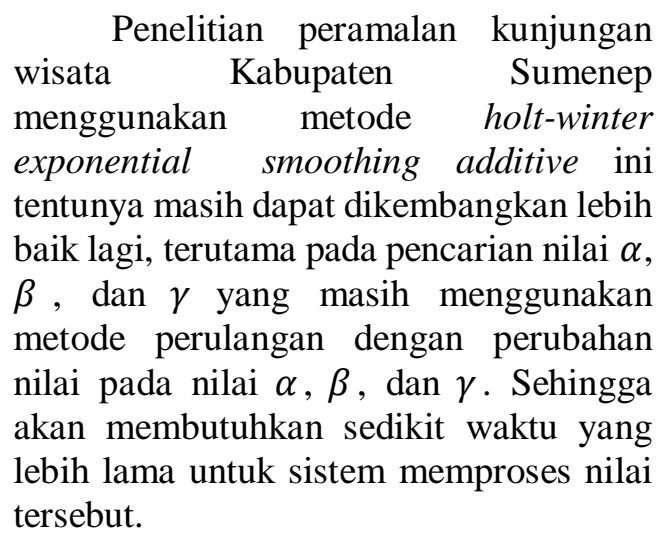

\section{DAFTAR PUSTAKA}

[1] BPS Kabupaten Sumenep, Kabupaten Sumenep Dalam Angka 2020. Sumenep: BPS Kabupaten Sumenep, 2020. doi: 1102001.3529.

[2] Y. M. Sari, "Penerapan Metode Holt-Winters' Additive Exponential Smoothing untuk Peramalan (Forecasting) Harga Bawang Merah di Yogyakarta," Universitas Sanata Dharma Yogyakarta, 2020.

[3] Wikipedia, "Forecasting," Wikipedia, 2021. https://en.wikipedia.org/wiki/Forec asting (accessed Oct. 22, 2021).

[4] A. P. R. Kusuma and S. Herawati, "Analisis Metode Perceptron untuk Prediksi Kunjungan Wisatawan Mancanegara," Jurnal Simantec, vol. 6, no. 2, pp. 85-90, Dec. 2017.

[5] D. A. Sasti, "Metode Pemulusan Eksponensial Holt-Winters untuk Peramalan Data Deret Waktu Musiman (Studi Kasus Data Jumlah kedatangan Wisatawan Mancanegara Melalui Bandara Ngurah Rai Tahun 2008-2016)," Universitas Lampung, 2017.
[6] A. Hartono, D. Dwijana, and W. Headiwidjojo, "Perbandingan Metode Single Exponential Smoothing dan Metode Exponential Smoothing Adjusted For Trend (Holt's Method) untuk Meramalkan Penjualan. Studi Kasus: Toko Onderdil Mobil 'Prodi, Purwodadi,"' Jurnal EKSIS, vol. 5, no. 1, pp. 8-18, 2015.

[7] Wikipedia, "Symmetric Mean Absolute Percentage Error," Wikipedia, Dec. 05, 2020. https://en.wikipedia.org/wiki/Sym metric_mean_absolute_percentage _error (accessed Oct. 23, 2021).

[8] D. al Mahkya, "Prediksi Nilai Ekspor Jawa Tengah Menggunakan Pendekatan Hierarchical Time Series," Institut Teknologi Sepuluh November, 2016. 